\section{THE EXCITO-SECRETORY SYSTEM.}

The following letter was accidentally omitted in our last:To the Editor of THE LANCET.

SIR,-I have transmitted to the London LANCET, by the present mail, a communication, in the form of a letter addressed to Dr. Marshall Hall, on the subject of the excitosecretory system of nerves, recently announced by him in THE LANCET.

The purport of my communication is, that I prefer a claim of priority in the above announcement, over both Dr. Marshall Hall and M. Claude Bernard, to whom Dr. Hall refers in his paper. In substantiation of my claim, I have quoted from the "Transactions" of the American Medical Association, and also from other published records.

I am induced to send my present paper to you, from the consideration of the character for liberality, fairness, and independence which your journal has acquired in this country, and also because I consider it one of the best mediums through which to reach the profession, both in Europe and America.

In addition to the consideration of fairness and the propriety, otherwise, of giving the paper in question an insertion, I would respectfully suggest that the subject itself must largely interest your professional readers; as there is no doubt that the views therein presented in regard to the excito-secretory system, must necessarily, ere long, enter considerably into the discussion of both physiological and pathological phenomena.

The letter was prepared expressly for publication in THE LANCET, as you will perceive; but being an editor myself, I have not thought that there was any impropriety in inserting it editorially in my own journal, with the statement " that it was prepared for and transmitted to the London LANCET." I send you the printed copy, with proof corrected.

Your compliance with my request to publish my letter to Dr. Marshall $\mathrm{Hall}$ in your next issue, or at some early date, will confer upon me an important favour.

I am, Sir, with much respect, your obedient servant,

Augusta, Georgia, U.S.A.

Henry F. Campeeli.

March 25th, 1857.

\section{SECRET TREATMENT OF CANCER AT THE MIDDLESEX HOSPITAL.}

To the Editor of THE LANCET.

SIR, - With reference to that portion of Dr. Rogers' letter in THE LANCET of the 2nd instant, wherein he states that $I$, having made the post-mortem examination in the case of which he speaks from this hospital, " believe that the patient's death was greatly hastened by interference with, and arrest of, the external manifestation in the breast," I beg to state that he labours under a misconception. To the question put by him to myself, in conversation, whether I did not consider it probable that the cancer in the lungs might have received a fresh impetus owing to the suppression of its development in the breast, I replied, as, in courtesy,-I could do no other than make some answer, - that such might be the case; but $I$ distinctly state that I did not express my opinion or belief such as bears out his representation.

I am, Sir, your obedient servant,

Middlesex Hospital, May, 1857.
House-Surgeon.

\title{
THE APPLICATION OF CHROMIC ACID TO WARTS.
}

To the Editor of THE LANCET.

Str,-In your "Mirror" of the 24th of January last, Mr. Marshall, of University College Hospital, calls attention to chromic acid as a new escharotic, and relates some cases where he had successfully employed it in the removal of warts from the genital organs. Profiting by his experience, I lately employed it in the following case:-

John $\mathrm{S}-$, aged nineteen, applied to me on April 12th, to be relieved of a warty growth affecting his nose and upper lip. The mass chiefly occupied the spaces at the sides of the alæ nasi, reaching down on the upper lip, and curling in towards the nostrils. It consisted of ragged ridges, with many deep clefts, and had been growing for six months. I applied a solution of chromic acid, of the strength recommended by $\mathrm{Mr}$. Marshall, (100 grains to a fluid ounce of distilled water) freely over and between. the ridges, the growth assuming a yellow

colour. The pain was scarcely complained of. A lead lotion was ordered to be applied night and morning. No dressing of any kind was used. He was to return in four days.

April 16th. - Much improved. One-half of the crop has disappeared, having dropped off; the surrounding skin was unaffected. Has had no pain whatever. Solution again applied.

20th. - Only some small portions remain on the left side, which were dealt with as before. A little of the solution which spread over the healthy skin was not wiped off.

24th.-Cured. The portion of skin touched by the solution has not been affected by it.

The entire removal of this growth without pain or inconvenience, the rapidity of the cure, and the safety of the remedy, show chromic acid to be a useful escharotic. I am glad to think that Mr. Marshall is to give us the result of his trials with it in other affections.

Arbroath, May, 1857.

I am, Sir, your obedient servant,

\section{THE BALLESWIDDEN MINES, CORNWALL.} To the Editor of THe LaIrCET.

Sin,-In your publication of May 2nd I perceive the following :-

"An admirable example, in order to avoid as far as possible the dangers of naked lights, has been lately set at the Balleswidden Mines in Cornwall, where works have been erected, and apparatus is now being fitted, for the purpose of introducing gas into the pit in place of candles."

'The foregoing paragraph requires elucidation. The Cornish miner invariably works with the naked light, and with impunity. No inflammable gas is eliminated in the Cornish mines, which are purely metalliferous. The county contains no collieries, and hence it happily enjoys a complete immunity from explosions.

The lighting the Balleswidden mines with gas can therefore have no relation to the safety of the miner. I am, Sir, your obedient servant,

James-street, Covent-garden, May, 1857. GEORGE CHOWEY.

\section{SCOTLAND.}

(FROM OUR EDINBURGH CORRESPONDENT.)

The winter session has drawn to a close without presenting any features of a more important character than those usually characterizing the winter term in Edinburgh. The recent meeting in favour of Poor-law Medical Reform, hearty and unanimous in its display of sympathy with the Poor-law surgeons of England, will doubtless aid in promoting the success of this desirable movement. The petition to Parliament, which has been drawn up, has been numerously signed by medical students, and will be presented by Mr. Adam Black. The organization of the meeting which has resulted in such a warm demonstration is principally due to the energy of $\mathrm{Mr}$. Wm. J. Cumming, to whom the success of his exertions must be highly gratifying.

Amonost the recent papers read before the Medico-Chirurgical Society, was a reply by Dr. Alison to Professor Bennett's "Observations on the Results of an Advanced Diagnosis and Pathology in the T'reatment of Internal Inflammations." Dr. Alison stated that the change in practice was the result of a change in the character of the diseased action in inflammation which formerly required bleeding, and that the remedy was then as necessary for the recovery of the patients as it is now uncalled for.

"Better late than never" seems to be the maxim Government has acted upon in reference to the chair of Military Surgery. It is understood that the professorship has been conferred upon Mr. Mathews, formerly a staff-surgeon of the first class, and who, during the cholera epidemic at Madeira, held a chief appointment. Report speaks of this gentleman as a clever operator and skilful surgeon, one well fitted to fill the chair of the late Sir George Ballingall.

The associated Societies of the University have, with few exceptions, closed till November next. The Hunterian Medical Society re-opens for the summer session. On this occasion Dr. John Glen will deliver an address on "Medical Education."

Although the late session has not been remarkable in its medical career, the "students' demonstrations" have at least 